\title{
A robust closed loop supply chain network design under different carbon emission policies
}

\author{
Farklı karbon emisyon politikaları altında sağlam bir kapalı döngü tedarik \\ zinciri şebeke tasarımı
}

\author{
Murtadha A. ALDOUKHI ${ }^{*}$ iD , Surendra M. GUPTA2 iD \\ 1,2 Department of Mechanical and Industrial Engineering, The College of Engineering, Northeastern University, Boston, USA. \\ aldoukhi.m@husky.neu.edu, s.gupta@northeastern.edu
}

Received/Geliş Tarihi: 05.07.2019, Accepted/Kabul Tarihi: 25.10.2019

doi: $10.5505 /$ pajes.2019.51460

*Corresponding author/Yazıșılan Yazar

Special Issue Article / Özel Sayı Makalesi

\begin{abstract}
Recently, the topic of designing a closed loop supply chain network has attracted researchers' attention due to the enormous financial and environmental benefits obtained from its practices. This paper addresses a new model of designing a closed loop supply chain network, which considers a downward product substitution policy under four carbon emission regulation policies: carbon cap, carbon tax, carbon cap-and-trade and carbon offset. To solve the assumed uncertainties of product demand and number of products returned, robust optimization is adopted. The aim of the model proposed is to select which facility to open/operate, select a transportation mode and determine the quantity of shipped and substituted products. We show a numerical example of using the four carbon emission regulation policies.
\end{abstract}

Keywords: Carbon regulatory policies, Closed loop supply chain, Downward substitution, Robust optimization

\section{Introduction}

It is undeniable that technology has raised our living standards. However, with the recent industrial revolution and the rapid development of technology came so much negative impact on the environment. Many products are disposed of while still functional; that is sometimes due to the customer's desire to upgrade to a newer technology, or due to changes occurring to the product, e.g. wear and tear. These products are called end of life (EOL) products. According to Ilgin and Gupta [1], EOL products also include non-functional returned rental products. The same applies to products returned due to dissatisfaction or for finding a better deal. If those products are severely damaged during transportation, or if they were found to be damaged due to the customer's misuse, they are regarded as EOL products. Other EOL products are returned for repair services but are found to be unrepairable.

The increased number of EOL products is imposing a great risk on the environment. Based on the reports from the Environmental Protection Agency (EPA), the United States produces over 4 billion tons of hazardous industrial waste annually. With the increase in industrial waste, the landfill areas where non-hazardous waste can be buried are diminishing at a dangerous rate.

Another potential risk is the emission of carbon dioxide, a factor of greenhouse gas (GHG) emissions, which is associated with
Öz

Son zamanlarda, kapalı bir döngü tedarik zinciri ağı tasarlama konusu araştırmacının dikkatini çekti. Bu, kapalı döngü tedarik zinciri uygulamalarından elde edilen çok büyük finansal ve çevresel faydalardan kaynaklanmaktadır. Bu makale, dört karbon emisyonu düzenleme politikası kapsamında așağı yönlü ürün ikame politikasını dikkate alan kapalı döngü tedarik zinciri ağı tasarlama modeline değinmektedir: karbon sınırı politikası, karbon vergisi politikası, karbon sınırı ve ticaret politikası ve karbon dengesi politikası Ürün talebindeki varsayılan belirsizlikleri ve iade edilen ürün sayısını çözmek için, sağlam optimizasyon benimsendi. Önerilen modelin amacl, hangi tesisin açılacağını / işletileceğini seçmek, bir nakliye modu seçmek ve sevk edilen ve ikame edilen ürünlerin miktarını belirlemektir. Dört karbon emisyonu düzenleme politikasını kullanmaya ilişkin sayısal bir örnek gösteriyoruz.

Anahtar kelimeler: Karbon düzenleme politikaları, Kapalı çevrim tedarik zinciri, Așağıya doğru ikame, Robust optimizasyon

environmental issues such as climate change and global warming. In 2014, the intergovernmental panel on climate change reported that between the year 2000 and 2010, there has been an increase of 10 billion metric tons of global emissions of GHGs [2]. The huge environmental impact of carbon emission has influenced researchers to investigate more about this topic and its impact on supply chain [3]-[8]. To mitigate the impact of carbon emission on the environment, four reduction policies have been utilized widely. These policies include carbon cap, carbon emission tax, cap-and-trade and carbon offset policy.

Environmentally Conscious Manufacturing (ECM) finds promising solutions to reduce the burden on the environment. It develops methods and implement green principles in the first stages of designing products, during transporting products to customers and finally during collecting and processing EOL products [9],[10]. Ilgin and Gupta [10] classified the themes falling under ECM to closed loop supply chain (CLSC), product design, and remanufacturing and disassembly. Among these themes, CSLC has received researchers' attention due to the tremendous benefits obtained financially and environmentally [11]-[14]. Today, many industries are employing the concept of CLSC in their practices, e.g. Xerox Company was able to save about $\$ 200$ millions by remanufacturing copy machines returned at the termination of their lease contracts. It was also the first company aiming towards zero waste in landfills and the first to successfully achieve this goal [15]. 
CLSC integrates forward and reverse supply chains. The forward supply chain (FSC) includes all activities, processes and operations that are involved in transforming raw materials to finalized products and delivering them to the consumers through distributors. The reverse supply chain (RSC), contrarily, includes the activities and operations of collection and recovery of returned products. This begins with collection of returned products, which either go through disassembly and recovery or disposal (depending on the condition of the product). Recovered products are finally delivered to the customers.

In a CLSC, planning decisions are divided into: strategic, tactical, and operational. Strategic planning primarily deals with longterm planning activities, that is, structuring a CLSC over the following few years (e.g. determination of the type of products to be processed and the number of facilities to run). Due to the long planning duration in strategic planning, the decision maker must bear in mind the high level of uncertainty anticipated for product demand. Tactical planning is mediumterm planning (e.g. months or weeks) that includes subcontracting and selecting a transportation mode to transport items across the network. Even though uncertainties have to be taken into consideration by the decision maker, compared with strategic planning, tactical planning is more precise due to its shorter term. Operational planning deals with short-term planning activities (e.g. days or hours), such as production planning and factory floor inventory matters. In terms of uncertainty level, operational planning deals with the least number of uncertainties when compared with strategic and tactical planning because of its shorter term [14].

Designing a CLSC network strategically needs further investigation. New models have to be created in order to resolve issues of considering uncertainties of product demand, number of returned products and the possibility of not satisfying customer demand. In this paper, we propose a model for designing a CLSC network that takes into account the uncertainties of product demand (both new and remanufactured) and number of products returned. It also allows new products to substitute remanufactured products in case of not meeting customer demand (downward substitution) while the network is restricted by various carbon policies: carbon cap, carbon emission tax, cap-and-trade and carbon offset policy.

The remainder of this paper is organized as follows: Section 2 presents a review of the current literature on CLSC network design and product substitution. Section 3 describes the carbon emission policies used in this paper. Robust optimization is the technique used to model uncertainties for the proposed problem as explained in section 4 . Section 5 describes the problem while section 6 presents the model notation and formulation. A numerical example is shown in section 7 and section 8 presents the conclusion and suggests future work.

\section{Literature review}

\subsection{CLSC network design}

The topic of CLSC network design has been discussed in the literature widely as one objective or multi-objective problems.

\subsubsection{Single objective}

Jayaraman, Guide and Srivastava [16] proposed a binary mixed integer programing (MIP) model to decide the optimum location for remanufacturing and distribution facilities, and to determine the most favorable amounts of transshipment, production and stocking for both cores and remanufactured products. Beamon and Fernandes [17] proposed a multi period mixed integer linear programing (MILP) model for a CLSC to find the ideal site for warehouses and to determine their sorting potential in addition to the amount of materials that must be transferred between each set of locations. Demirel and Gökçen [18] developed a (MIP) model to find the most favorable amounts for manufacturing, remanufacturing, and transportation in addition to the ideal facility sites for disassembly, collection and distribution. Özceylan and Paksoy [19] presented a general CLSC network model, which consists of forward and reverse parts, and an MIP model was presented to optimize the network. The forward supply chain network included suppliers of raw materials, plants, retailers, and consumers. On the other hand, the reverse supply chain network consisted of consumers, collection centers, disassembly centers, refurbishing centers, and plants. The transportation of products in the two parts was considered under a dynamic time horizon. Kalaitzidou, Longinidis and Georgiadis [20] proposed MILP model that aimed to determine the optimum network structure that is able to satisfy market demands while employing the minimum operational cost and overall capital. It is noticed that none of these authors considered uncertainties in their developed models. Other researchers developed single objective models under uncertainties using stochastic programing, fuzzy programing, robust optimization or integrated techniques together [6],[13], [21]-[27]

\subsubsection{Multiple objectives}

Designing a CLSC network considering multiple objectives has attracted researchers' attention. Ilgin, Gupta and Battaïa [28] and Ilgin and Gupta [29] conducted a literature review showing the usage of Multiple Criteria Decision Making (MCDM) techniques in designing a CLSC network, and ECM generally. Amin and Zhang [30] proposed weighted-sum and distance methods to reduce the total cost and defect rate objectives of CLSC network design. Shi, Liu, Tang \& Xiong [31] developed a model to design a CLSC network taking into account three objectives: minimizing the overall system cost, minimizing carbon emission and maximizing the responsiveness of CLSC network. Nukala and Gupta [32] proposed a model using physical programing to design a CLSC network. However, in these papers, uncertainties in the models were not considered.

Developing a multi-objective model to design a CLSC network under uncertainties has attracted researchers' interest to work in this area. Amin and Zhang [33] considered product demand and number of returned products as uncertainty parameters in designing a CLSC that includes multiple plants, collection centers, demand markets, and products. They used weighted sum and $\varepsilon$-constraints methods. In their proposed model, the first objective considered was to minimize the total cost while the second objective was to consider the environmental issues. Fuzzy multi-objective method has been used widely in the literature. Paksoy, Pehlivan and Özceylan [34] developed a model to design a CLSC network in a green framework. The first and second objectives were to reduce the costs of transportation for the supply chain's forward and reverse logistics while the third objective was to reduce the overall CO2 emissions, and the fourth objective was to promote using recyclable materials to the consumers as an environment- 
friendly practice that will also reduce the raw material cost. Pishvaee, Rabbani and Torabi [35] proposed a model that considered the uncertainty of the demand and all related costs as well as the capacity at each plant location. In the proposed model, the first and second objectives were to minimize the overall cost and overall environmental risk, respectively. Another fuzzy multi-objective model was developed by Özceylan \& Paksoy [36] for designing a CLSC network, where the uncertainties were the objective functions, capacity, demand constraints and the reverse rate. Their objectives were to minimize the manufacturing and distribution costs and to cut down the fixed cost of opening a plant. Maximizing the profit and minimizing the environmental hazards were also the two objectives of Jindal \& Sangwan's [37] study. An attempt to integrate a green and sustainable CLSC network was done by Zhen, Huang and Wang [38]. To represent the assumed uncertainty of demand in their proposed model, the scenariobased method was used.

The majority of the studies considered recycling activities as recovery processes of the reverse flow in the CLSC network. Only a few studies developed models to design a CLSC network where remanufacturing was considered a source of supply. Even the studies considering remanufacturing as a source of supply did not discriminate between new and remanufactured products demand although they should be differentiated for two reasons: the quality of remanufactured products, which affects its selling price, and government regulations (e.g. in the USA market) that enforce labeling remanufactured products differently than new products [39]. To the best of our knowledge, the only work in this area was done by Ghafarimoghadam, Karimi, Mousazadeh, \& Pishvaee, [40]. However, in their proposed model, environmental issues were not taken into consideration although their importance was illustrated by various studies that investigated the potential impact of carbon regulations on production decisions, inventory management decisions, and strategic decisions as well [2],[4],[5],[8],[41]. In addition, in their proposed work, they assumed all returned products have a uniform level of quality. However, as illustrated by Gupta [1], EOL products are returned for a wide range of reasons, from the slightly used products to the severely damaged ones, and therefore, their quality level must be differentiated. Mohammed et al. [2] also proposed a model to design a CLSC network under uncertainty of customer demand, products returned and carbon emission parameters. Mohammed et al. [42] extended the model of Mohammed et al. [2], in which they considered different uncertainty sets to represent the model uncertainty under the carbon tax and carbon trading policies. However, in both models, the product recovery processes applied on the returned products were recycling activities only without considering remanufacturing activities.

\subsection{Network design under carbon regulation policies}

Benjaafar et al. [5] explained how optimization models for supply chain operational decision integrating various carbon policies such as carbon cap, carbon tax rate, carbon cap-andtrade, and carbon offset policies. Jin et al. [4] analyzed the impact of carbon emission tax, inflexible cap, and cap-and-trade carbon policies on major retailers supply chain strategic and transportation mode selection decisions by proposing optimization models. Fareeduddin et al. [8] integrated reverse logistics to Jin et al. previous model to design CLSC network under the same carbon policies. Mohammed et al. [2] extended the model proposed by Fareeduddin et al. [8], in which they took into consideration the uncertainties of carbon emission related parameters.

\section{$2.3 \quad$ Product substitution}

Generally, when one of two products $\mathrm{i}$ and $\mathrm{j}$ satisfies the demand of the other, it is called product substitution.

Product substitution mechanism is described in three scenarios; assortment based substitution, inventory based substitution and price based substitution. To best describe each scenario, the following examples are given. Assortment- based substitution happens when a customer visits a drug store to purchase pain relief drug $\mathrm{A}$, but while he is in the store, decides to purchase a newer version of pain relief drug $A$, which is pain relief drug $B$. When a company that produces product $A$ and product $B$ runs out of stock of product $A$ and replaces it with product $B$ which is available, the substitution is called inventory-based substitution. Price-based substitution is found when a passenger desires to purchase an economy class ticket, but finds that the price of that class has increased, so he chooses to book a business class ticket instead [43]. In this research, we consider the case of inventory-based substitution.

In inventory-based substitution, when product i substitutes product $\mathrm{j}$ and not vice versa, it is a one-way substitution. It is called downward substitution when the quality of product i is higher than the quality of product $j$, and product i substitutes product $j$. It is observed that product substitution can reduce inventory cost and level, lower set up cost and time, and increase customer satisfaction [44].

Bayindir, Erkip, and Güllü [45],[46] conducted two studies discussing the situation when new products can replace remanufactured products while they are sectioned to two separate markets and the production capability is infinite and finite. Li, Chen, and Cai [47] studied an incapacitated multi product, multi period, and stochastic remanufacturing systems with part substitution where no shortage, blockage or disposal were permitted. Piñeyro and Viera [48] studied a problem of lot-sizing when there are two demand lines for new and remanufactured products, in this problem, new products can substitute remanufactured products. Ahiska, Gocer and King [39] studied and distinguished different inventory control policies of a system that combines manufacturing and remanufacturing and allows downward substitution under stochastic demand and products returned.

This work contributes to the literature with the following:

- Considering different quality levels of returned products,

- Discriminating demand of new products and that of remanufactured products,

- Allowing product substitution using downward product substitution policy,

- Considering four carbon emission regulations; carbon cap, carbon tax, carbon cap-and-trade and carbon offset and their effect on quantity of product substitution.

\section{Carbon emission policies}

Four carbon emission policies were introduced in order to limit and reduce greenhouse gas (GHG), specifically for carbon dioxide emission; carbon cap, carbon tax, carbon cap-and-trade 
and carbon offset policy. These policies influence strategic, operational and logistic activities in a supply chain [5],[7],[49].

\subsection{Carbon cap policy}

Cap refers to the maximum amount of carbon allowed to be emitted. In this policy, all activities emitting carbon are restricted by a cap. It is modeled as a constraint added to the problem.

\subsection{Carbon tax policy}

Under this policy, all activities, which are associated with emitting carbon, are penalized financially by a tax per unit of carbon emitted. On the contrary of the carbon cap policy, there is no need to add a new constraint to the problem. Only the objective function is extended to include the financial penalty.

\subsection{Carbon cap-and-trade policy}

This policy utilized the same concept described in the carbon cap policy. However, this policy allows trading unused or overused carbon. It is possible to sell unused amounts of carbon if the carbon emitted is less than the carbon cap. Nevertheless, if the carbon emitted is more than the prescribed carbon cap, credits of carbon emission are purchased to maintain activities consistent with the supply chain.

\subsection{Carbon offset policy}

This policy is comparable to the carbon cap-and-trade policy except that it does not allow selling the unused amount of carbon, which means, no additional profit is gained. It only buys carbon credits if the supply chain activities require emitting more carbon than their prescribed carbon cap.

In this study, we consider carbon emission resulted from production activities, transportation activities and product disposal activities [3]-[8].

To model the problem discussed in this paper considering uncertainty in terms of robustness, we use robust optimization.

\section{Robust optimization}

Mulvey, Vanderbei and Zenios [50] proposed a robust optimization approach that takes into account uncertain parameters. Besides the advantage of this approach in fitting problems that have a high degree of uncertainty, it also does not require knowledge of the probability distribution of the uncertainty parameter. It represents the uncertainty parameters as a set of scenarios with discrete probabilities. It includes two robustness types which are solution robustness and model robustness. Solution robustness is when the solution is almost optimal for any realization of the scenario. When the solution is nearly feasible for any realization of the scenario, it is called Model robustness. The following briefly explains the primary robust optimization LP model:

$$
\begin{gathered}
\text { MIN Z }=c^{T}+d^{T} y \\
A x=b \\
B x+C y=e \\
x, y \geq 0
\end{gathered}
$$

where $\mathrm{x}$ represents the vector of design variables and $\mathrm{y}$ represents the vector of control variables. The structural constraint's coefficients in Eq. (2) do not have an association with any uncertainty. However, the coefficients of control constraints denoted in Eq. (3) are subjected to noise. Mulvey, Vanderbei and Zenios [50], proposed a set of scenarios $(\mathrm{SC} \in \Omega$ ) in addition to the probability in order to model the uncertain parameters of every scenario $\rho_{\varepsilon}\left(\sum \rho_{\varepsilon}=1\right)$.

Mulvey, Vanderbei and Zenios [50] also proposed the mean/variance formulation in order to manage the uncertainties in the decision environment of a supply chain design, in which $\lambda$ represents a variance weighting factor.

$$
\begin{gathered}
\text { MIN Z }=\sum_{s c} \rho_{s c} \xi_{s c}+\lambda \sum_{s c} \rho_{s c}\left(\xi_{s c}-\sum_{s c^{\prime}} \rho_{s c^{\prime}} \xi_{s c \prime}\right)^{2} \\
A x=b \\
B_{s c} x+C_{s c} y_{s c}+\delta_{s c}=e_{s c} \\
x, y_{s c}, \delta_{s c} \geq 0
\end{gathered}
$$

Because of the quadratic formulation's high computational effort, $\mathrm{Yu}$ and $\mathrm{Li}$ [51] presented a substitute for it (5), The new formulation uses an absolute deviation formulation to replace the formulation of the variance in the objective function (9). In addition, $\mathrm{Li}$ [52] presented a linearized optimization model (10):

$$
\begin{gathered}
\mathrm{MINZ}=\sum_{s c} \rho_{s c} \xi_{s c}+\lambda \sum_{s c} \rho_{s c}\left|\xi_{s c}-\sum_{s c \prime} \rho_{s c^{\prime}} \xi_{s c^{\prime}}\right| \\
\mathrm{MINZ}=\sum_{s c} \rho_{s c} \xi_{s c}+\lambda \sum_{s c} \rho_{s c}\left[\left(\xi_{s c}-\sum_{s c \prime} \rho_{s c \prime} \xi_{s c \prime}\right)\right. \\
\left.+2 \theta_{s c}\right] \\
A x=b \\
B_{s c} x+C_{s c} y_{s c}+\delta_{s c}=e_{s c} \\
\xi_{s c}-\sum_{s c} \rho_{s c} \xi_{s c}+\theta_{s c} \geq 0 \\
x, y_{s c}, \delta_{s c} \geq 0
\end{gathered}
$$

In the case of $\xi_{\mathrm{sc}}-\sum_{\mathrm{sc}} \rho_{\mathrm{sc}} \xi_{\mathrm{sc}} \geq 0$, then $\theta_{\mathrm{sc}}=0$ and $\mathrm{Z}=$ $\sum_{\mathrm{sc}} \rho_{\mathrm{sc}} \xi_{\mathrm{sc}}+\lambda \sum_{\mathrm{sc}} \rho_{\mathrm{sc}}\left[\left(\xi_{\mathrm{sc}}-\sum_{\mathrm{sc}} \rho_{\mathrm{sc}} \xi_{\mathrm{sc}}\right)\right]$, otherwise if $\xi_{\mathrm{sc}}-$ $\sum_{\mathrm{sc}} \rho_{\mathrm{sc}} \xi_{\mathrm{sc}} \leq 0$, then $\theta_{\mathrm{sc}}=\sum_{\mathrm{sc}} \rho_{\mathrm{sc}} \xi_{\mathrm{sc}}-\xi_{\mathrm{sc}}$ and $\mathrm{Z}=$ $\sum_{\mathrm{sc}} \rho_{\mathrm{sc}} \xi_{\mathrm{sc}}+\lambda \sum_{\mathrm{sc}} \rho_{\mathrm{sc}}\left[\left(\sum_{\mathrm{sc}} \rho_{\mathrm{sc}} \xi_{\mathrm{sc} \prime}-\xi_{\mathrm{sc}}\right)\right]$, Therefore, it is proved, that the solutions of $(10,11,12,13,14)$ are identical to that of (9).

\section{Problem description}

A CLSC network consists of raw material suppliers, plant centers, distribution centers, collection centers and multiple market locations. In the forward flow, the plant centers produce new products using the raw materials delivered from the suppliers and also remanufacture the returned products. The finished products are shipped to different market locations through the distribution centers. In the reverse flow, the EOL products, which are returned to market locations are shipped to the collection centers, where they are inspected and either shipped for remanufacturing or disposed of. Due to the different conditions of the returned products, different quality levels are considered. 
Environmental impact, represented by carbon cap policy, carbon tax policy, carbon cap-and-trade policy and carbon offset policy, is taken into consideration, in which production activities in each plant center are associated with carbon emission factors. In addition, since product transportation is a considerable contributor to carbon emission and in order to provide a close form to a real supply chain, we consider several modes of transportation with a limited capacity and different carbon emission factors. Product disposal processes are also associated with carbon emission.

Due to the price difference between new and remanufactured products, and due to the federal government regulations that require differentiating these two products, demand of new products and remanufactured products are distinguished [39]. This takes place in market locations which either demand new products, remanufactured products or both. The demand of each type of product is assumed as an uncertainty parameter since demand fluctuate seasonally, customer preferences change and market competition is very high.

There is a high level of uncertainties associated with RSC activities due to the time to receive returned products being unknown in addition to the quantity and quality of the products returned [1]. Therefore, we consider the number of returned products as an uncertainty parameter. We allow a one-way downward substitution in the proposed model with a strict substitution policy, in which a new product fulfills the demand of a remanufactured product whenever it is not possible to satisfy the customer demand of the remanufactured product.

In order to formulate the above problem, we use a robust optimization approach in which the uncertainty parameters are the new and the remanufactured product demand in addition to the number of the returned product. The goal is to reduce the total system cost by finding:

- The number and location of each facility type,

- Select the raw material suppliers and the supplied quantity,

- The amount of product to produce and shipped in the CLSC network,

- Quantity of new products to substitute remanufactured products and the transportation mode to be used between facilities.

The following assumptions are considered:

1. Each raw material supplier, plant, distribution and collection center have a capacity restriction and a known number and known locations,

2. The market number and locations are predefined,

3. The cost of opening facilities depends on the capacity and location of the facility,

4. The cost of purchasing raw materials includes the cost to deliver raw materials from the suppliers to the manufacturing facility,

5. The cost of remanufacturing products includes disassembly, and upgrade/repair costs,

6. The returned products are classified to different quality levels,

7. The cost to remanufacture returned products depends on their quality condition at the time of the return; products returned with major defects cost more to remanufacture,

8. At any market location, it is accepted to substitute a remanufactured product with a new product.

\section{Model notation and formulation}

\subsection{Model notation}

The following notation is used for the model mathematical formulation.

Sets:

PR: set of products \{new, remanufactured\}

$\mathrm{S}$ : set of raw materials/component suppliers $\{1,2,3 \ldots \mathrm{s}\}$.

M: set of candidate locations for plant centers $\{1,2,3 \ldots \mathrm{m}\}$.

$W$ : set of candidate locations for warehouse centers $\{1,2,3 \ldots$ w\}.

C: set of market locations $\{1,2,3 \ldots c\}$.

$\mathrm{H}$ : set of candidate locations for collection centers $\{1,2,3 \ldots \mathrm{h}\}$.

MOD: set of candidate locations for transportation modes $\{1,2$, 3 ... mod\}.

K: quality level of returned products $\{1,2,3 \ldots \mathrm{k}\}$.

SC: set of scenarios $\{1,2,3 \ldots \mathrm{sc}\}$.

General Parameters:

$D M_{p r, c}^{s c}$ : the market location c's demand of product pr under scenario sc.

$R_{c}^{s c}$ : returned product to the market location c under scenario sc.

$B_{k}$ : fraction of quality level $\mathrm{k}$ of returned product.

$\mathrm{CO}$ : needed number of raw materials to produce a unit of new product.

$F R A C_{c, p r}$ : substitution fraction at the market location $\mathrm{c}$ of product pr.

$\alpha$ : fraction of returned products that is disposed of.

$\lambda$ : weighing factor to measure solution robustness.

$\omega$ : weighting factor to measure model robustness.

$\rho_{s c}$ : probability of scenario sc.

Fixed costs:

$F M_{m}$ : construction cost of the plant center located in $\mathrm{m}$.

$F W_{w}$ : construction cost of the warehouse center located in w.

$\mathrm{FH}_{h}$ : construction cost of the collection center in location $\mathrm{h}$.

Unit Costs:

$P C_{m}$ : production cost/unit of new products at the plant center located in $\mathrm{m}$.

$R C C_{k, m}$ : remanufacturing cost/unit of returned products of quality level $\mathrm{k}$ at the plant located in $\mathrm{m}$.

$I N S_{h}$ : cost of inspecting and sorting returned products at the collection center located in $\mathrm{h}$.

$P_{s, m}$ : component purchasing cost from supplier s by the plant center located in $\mathrm{m}$.

${ }_{C R M S U B} B_{p r, p x}$ : cost of substituting product pr by product $\mathrm{px}$.

Shipping costs: 
TRMW $W_{m, w, m o d}$ : shipping cost/unit of product from the plant center located in $\mathrm{m}$ to the warehouse center located in $\mathrm{w}$ using mod transportation mode.

$T R W C_{w, c, \text { mod }}$ : shipping cost/unit of product from the warehouse center located in $\mathrm{w}$ to the market location $\mathrm{c}$ using mod transportation mode.

$T R C H_{c, h, \text { mod }}$ : shipping cost/unit of returned product from the market location $\mathrm{c}$ to the collection center located in $\mathrm{h}$ using mod transportation mode.

TRHM $M_{h, m, \text { mod }}$ : shipping cost/unit of returned product from the collection center located in $\mathrm{h}$ to the plant center located in $\mathrm{m}$ using mod transportation mode.

Capacity parameters:

$C A P M_{m}$ : production capacity of the plant center located in $\mathrm{m}$, in units.

$C A P W_{w}$ : the warehouse center capacity located in $\mathrm{w}$, in units.

$\mathrm{CAPH}_{h}$ : capacity of the collection center located in $\mathrm{h}$, in units.

$C A P S_{S}$ : capacity of the supplier s, in units.

Load capacities of transportation mode:

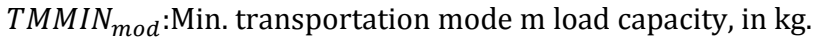

$T M M A X_{\text {mod }}$ :Max. transportation mode m load capacity, in kg.

Carbon emission parameters:

$E P_{m}$ : at the plant center located in $\mathrm{m}$, a factor of emitting carbon in $\mathrm{kg}$ due to production of a unit of new product or remanufacturing a unit of product.

$E T M W_{m, w, m o d}$ : a factor of emitting carbon in $\mathrm{kg} / \mathrm{unit}$ of product shipped from the plant center located in $\mathrm{m}$ to the warehouse center located in w using mod transportation mode.

$E T W C_{w, c, \text { mod }}$ : a factor of emitting carbon in $\mathrm{kg} / \mathrm{unit}$ of product shipped from the warehouse center located in $w$ to the market location c using mod transportation mode.

$E_{C T C H}, h$, mod a factor of emitting carbon in $\mathrm{kg} /$ unit of EOL product returned to the market location $\mathrm{c}$ and shipped to the collection center located in $\mathrm{h}$ using mod transportation mode.

ETHM $_{h, \text { m,mod }}$ : a factor of emitting carbon in $\mathrm{kg} /$ unit of returned product shipped from the collection center located in $\mathrm{h}$ to the plant center located in $\mathrm{m}$ in location $\mathrm{m}$ using mod transportation mode.

ETDIP : a factor of emitting carbon in $\mathrm{kg} /$ unit of product that is disposed of.

$C A P$ : carbon strict cap.

$T A X$ : tax penalty paid/ kg emitted.

$C P^{+}$: price/ $\mathrm{kg}$ of carbon purchased in the carbon market.

$C P^{-}$: price/ kg of carbon sold in the carbon market.

$O P$ : offset price of carbon per kg.

Design variables:

$Y M_{m}: 1$ if construction of the plant center is in location $\mathrm{m}, 0$ otherwise.

$Y W_{w}: 1$ if construction of the warehouse center is in location w, 0 otherwise.

$Y C_{h}: 1$ if construction of the collection center is in location h, 0 otherwise.
$Y T M W_{m, w, m o d}: 1$ if transportation mode mod is selected to ship products between the plant center located in $\mathrm{m}$ and the warehouse center located in w, 0 otherwise.

$Y T W C_{w, c, \text { mod }}: 1$ if transportation mode mod is selected to ship products between the warehouse center located in $w$ and the market location c, 0 otherwise.

$Y_{C C H} H_{c, h \text { mod }} 1$ if transportation mode mod is selected to ship products between the market location $\mathrm{c}$ and the collection center located in h, 0 otherwise.

YTHM $_{h, \text { m,mod }}$ : 1 if selection of transportation mode mod is chosen between the collection center located in $\mathrm{h}$ and the plant center located in $\mathrm{m}, 0$ otherwise.

Control variables:

$X P_{p r, m}^{s c}$ : production amounts of product $\mathrm{pr}$, which is produced in the plant center located in $\mathrm{m}$ under scenario sc.

$X Q S M_{s, m}^{s c}$ : amount shipped of raw materials from the supplier $s$ to the plant center located in $\mathrm{m}$ using mod transportation under scenario sc.

$X Q M W_{p r, m, w}^{m o d}:$ : amount of product pr shipped from the plant center located in $\mathrm{m}$ to the warehouse center located in $\mathrm{w}$ under scenario sc.

$X Q W C_{p r, p x, w, c}^{m o d, s c}$ : amount of product $\mathrm{pr} / \mathrm{px}$ shipped from the warehouse center located in $\mathrm{w}$ to the market location $\mathrm{c}$ using mod transportation mode under scenario sc.

$X R Q C H_{k, c, h}^{m o d, s c}$ : amount of returned products with quality level $\mathrm{k}$ shipped from the market location $\mathrm{c}$ to the collection center located in h using mod transportation mode under scenario sc. $X R Q H M_{k, h, m}^{\text {mod,sc }}$ : amount of returned products with quality level $\mathrm{k}$ shipped from the collection center located in $\mathrm{h}$ to the plant center located in $\mathrm{m}$ using mod transportation mode under scenario sc.

$D I S P_{k, h}^{S c}$ : amount of returned products with quality level $\mathrm{k}$ that are assigned for disposal in the collection center located in $h$ under scenario sc.

$U_{p r, c}^{s c}$ : amount of unsatisfied product pr which can be substituted at the market location c under scenario sc.

$E C_{S c}^{+}$: amount of carbon credit purchased under scenario sc.

$E C_{s c}^{-}$: amount of carbon credit sold under scenario sc.

$\delta D P_{c, p r}^{s c}$ : violation of demand constraint, amount of not meeting the market location $\mathrm{c}$ demanding product pr under scenario sc. $\delta R E_{c}^{s c}$ : violation of the number of returned products constraint. $\theta_{s c}$ : deviation for violation of the mean under scenario sc.

\subsection{Model formulation}

\subsubsection{No carbon emission policy is considered}

The basic formulation that considers the uncertainty of product demand and number of returned products is as follows: The total cost (TC) includes the total fixed cost (TFC), the total cost of purchasing raw materials $\left(T R M_{s c}\right)$, the total production cost $\left(T P C_{s c}\right)$, the total transportation cost $\left(T T C_{s c}\right)$, the total collection cost $\left(T C C_{s c}\right)$ and the total product substitution cost $\operatorname{TCSUB}_{S c}$. 


$$
\begin{gathered}
T C_{s c}=T F C+T R M_{s c}+T P C_{s c}+T T C_{s c}+T C C_{s c} \\
+T C S U B_{s c} \\
\forall s C
\end{gathered}
$$

The total fixed cost includes all costs involved with opening a new facility in the CLSC: opening plant center, a warehouse and a collection center.

$$
\begin{gathered}
T F C=\sum_{\mathrm{m}}\left(\mathrm{FM}_{\mathrm{m}} * \mathrm{YM}_{\mathrm{m}}\right)+\sum_{\mathrm{w}}\left(\mathrm{FW}_{\mathrm{w}} * \mathrm{YW}_{\mathrm{w}}\right) \\
+\sum_{\mathrm{H}}\left(\mathrm{Fh}_{\mathrm{H}} * \mathrm{Yh}_{\mathrm{hw}}\right)
\end{gathered}
$$

The total cost of purchasing raw materials $\left(T R M_{s c}\right)$ includes the cost of delivering raw materials from suppliers to the manufacturing facility.

$$
T R M_{s c}=\sum_{s} \sum_{m} P_{s, m} * X Q S M_{s, \mathrm{~m}}^{s c} \quad \forall s c
$$

The total production cost $\left(T P C_{s c}\right)$ includes the cost to produce a new product $\left(T P C I_{s c}\right)$ and the cost to remanufacture a returned product $\left(T P C I I_{s c}\right)$.

$$
\begin{gathered}
T P C_{s c}=T P C I_{s c}+T P C I I_{s c} \\
T P C I_{s c}=\sum_{m} P C_{m} * X P_{p r, m}^{s c} \quad \forall s c, p r=n e w \\
T P C I I_{s c}=\sum_{k} \sum_{h} \sum_{m} \sum_{m o d} R C C_{k, m} * X R Q H M_{k, h, m}^{m o d, s c} \quad \forall s c
\end{gathered}
$$

The total transportation cost $\left(T T C_{S C}\right)$ is the cost of shipping a unit of product among all facilities in the CLSC network.

$$
\begin{aligned}
& T T C_{S C} \\
& =\sum_{m} \sum_{w} \sum_{m o d} T R M W_{m, w, \bmod } * X Q M W_{p r, m}^{\text {mod }, s c} \\
& +\sum \sum \sum T R W C_{w, c, \bmod } * X Q W C_{p r, p x, w, c}^{\bmod , s c} \\
& +\sum_{k} \sum_{c}^{c} \sum_{h}^{\bmod } \sum_{\text {mod }} T R C H_{c, h, \text { mod }} * X R Q C H_{k, c, h}^{\text {mod sc }} \\
& +\sum_{k} \sum_{h}^{c} \sum_{m}^{h} \sum_{m o d}^{\bmod } \operatorname{TRHM}_{h, \mathrm{~m}, \mathrm{mod}} \\
& \text { * XRQHM } M_{k, h \text {, }, s c}
\end{aligned}
$$$$
\forall s c
$$

The total collection cost $\left(T C C_{S c}\right)$ is related to inspection and sorting of returned products at the collection centers

$$
T C C_{s c}=\sum_{k} \sum_{c} \sum_{h} \sum_{m o d} I N S_{h} * X R Q C H_{k, c, h}^{\text {mod,sc }} \quad \forall s c
$$

The total product substitution cost $\left(T C S U B_{s c}\right)$ is the cost of substituting remanufactured products by new products.

$$
\begin{gathered}
\operatorname{TCSUB}_{s c}=\sum_{w} \sum_{c} \sum_{m o d} \sum_{p r} \sum_{p x} C R M S U B_{p r, p x} \\
* X Q W C_{p r, p x, w, c}^{m o d}
\end{gathered}
$$

Therefore, the objective function is formulated as follow:

$$
\begin{array}{rl}
\operatorname{Min} Z=\sum_{s c} \rho_{s c} & T C_{s c}+\lambda \sum_{s c} \rho_{s c}\left[\left(T C_{s c}-\sum_{s c \prime} \rho_{s c \prime} T C_{s c^{\prime}}\right)\right. \\
& \left.+2 \theta_{s c}\right] \\
& +\omega \sum_{s c} \sum_{p r} \sum_{c} \rho_{s c} \delta D P_{c, p r}^{s c}+\delta R E_{c}^{s c}
\end{array}
$$

The model constraints are as follow;

New products are produced using the raw materials delivered from all suppliers.

$$
\sum_{s} X Q S M_{s, m}^{s c}=\mathrm{CO} * X P_{p r, m}^{s c} \quad \forall m, s c, p r=n e w
$$

Remanufactured products are produced using all quality levels of returned products delivered from all collection centers using all transportation modes.

$$
X P_{p r, m}^{s c}=\sum_{k} \sum_{h} \sum_{\substack{\text { mod } \\=\text { remanufactured }}} X R Q H M_{k, h, m}^{\text {mod,sc }} \forall m, s c, p r
$$

Any products produced at any plant center, are shipped to all warehouses using all transportation modes.

$$
X P_{p r, m}^{s c}=\sum_{w} \sum_{m o d} X Q M W_{p r, m, w}^{m o d, s c} \quad \forall m, s c, p r
$$

Any product shipped from any plant to any warehouse is shipped to all market locations using all transportation modes.

$\sum_{m} \sum_{m o d} X Q M W_{p r, m, w}^{m o d, s c}=\sum_{c} \sum_{m o d} \sum_{p x} X Q W C_{p r, p x, w, c}^{m o d, s c}$

$\forall w, s c, p r$

The EOL returns of each product with different quality levels equals the shipments of these returns to the collection centers using all transportation modes.

$\sum_{h} \sum_{m o d} X R Q C H_{k, c, h}^{m o d, s c}+\delta R E_{c}^{s c}=B_{k} * R E_{c}^{s c}$

$\forall c, s c, k$

A part of the returned products of each quality level shipped from all market locations to any collection center using all transportation modes is disposed of.

$D I S P_{k, h}^{s c}=\alpha * \sum_{c} \sum_{m o d} X R Q C H_{k, c, h}^{m o d, s c}$

$\forall k, h, s c$

The rest of the products are shipped to all plant centers for remanufacturing using all transportation mode.

$$
\sum_{m} \sum_{m o d} X R Q H M_{k, h, m}^{m o d, s c}=(1-\alpha) * \sum_{c} \sum_{m o d} X R Q C H_{k, c, h}^{m o d, s c}
$$


The demand of a product can be satisfied either directly or indirectly. Otherwise, violation of not meeting the demand (shortage).

$\sum_{W} \sum_{m o d} X Q W C_{p r, p r, w, c}^{m o d, s c}+U_{c, p r}^{s c}+\delta D P_{c, p r}^{s c}=D M_{c, p r}^{s c}$

$\forall s c, c, p r$

At any market location, satisfying the demand of any product indirectly is done by a substituted product.

$U_{c, p r}^{s c}=\sum_{W} \sum_{m o d} \sum_{p x \neq p r} X Q W C_{p x, p r, w, c}^{m o d, s c}$

$\forall s c, c, p r$

At any market location, the fraction, which shows the acceptance probability of substituting a product, determines the number of products substituted.

$\sum_{W} \sum_{m o d} \sum_{p x \neq p r} X Q W C_{p x, p r, w, c}^{m o d, s c} \leq F R A C_{c, p x, p r} * U_{c, p r}^{s c}$

$\forall s c, c, p r, p x$

We allow shipping products between open facilities only using any transportation mode.

$$
\begin{array}{cc}
Y T M W_{m, w, \text { mod }} \leq Y M_{m} & \\
Y T H M_{h, m, \text { mod }} \leq Y M_{m} & \\
Y T W C_{w, c, \text { mod }} \leq Y W_{w} & \forall h, m, \text { mod } \\
& \forall w, c, \text { mod } \\
Y T M W_{m, w, \text { mod }} \leq Y W_{w} & \\
Y T C H_{c, h, \text { mod }} \leq Y C_{h} & \forall m, w, \bmod \\
Y T H M_{h, \text { m,mod }} \leq Y C_{h} & \\
& \forall c, h, \text { mod } \\
& \forall h, m, \bmod
\end{array}
$$

We ensure that only one transportation mode is selected to ship a product.

$$
\begin{aligned}
& \sum_{\bmod } Y T M W_{m, w, m o d} \leq 1 \\
& \sum_{m o d} Y T H M_{h, m, \bmod } \leq 1 \\
& \sum_{m o d} Y T W C_{w, c, m o d} \leq 1
\end{aligned}
$$$$
\forall h, m
$$

$\forall m, w$

$$
\sum_{\bmod } Y T C H_{c, h, \bmod } \leq 1
$$

$$
\forall c, h
$$

We ensure shipping products using any transportation mode is within certain, minimum and maximum, capacity limitation.

$$
\sum_{p r} X Q M W_{p r, m, w}^{\text {mod,sc }} \geq T M M I N_{\text {mod }} * Y T M W_{m, w, \text { mod }}
$$

$\forall m, w, \bmod , s c$

$\sum_{p r} X Q M W_{p r, m, w}^{m o d, s c} \leq T M M A X_{m o d} * Y T M W_{m, w, m o d}$

$\forall m, w, \bmod , s c$

$$
\sum_{p r} \sum_{p x} X Q W C_{p r, p x, w, c}^{m o d, s c} \geq T M M I N_{m o d} * Y T W C_{w, c, m o d}
$$

$\forall w, c, \bmod , s c$

$\sum_{p r} \sum_{p x} X Q W C_{p r, p x, w, c}^{m o d, s c} \leq T M M A X_{m o d} * Y T W C_{w, c, \bmod }$

$\forall w, c, \bmod , s c$

$$
\sum_{k} X R Q C H_{k, c, h}^{m o d, s c} \geq T M M I N_{\text {mod }} * Y T C \mathrm{H}_{c, h, \bmod }
$$

$\forall c, h, \bmod , s c$

$$
\sum_{k} X R Q C H_{k, c, h}^{\text {mod,sc }} \leq T M M A X_{m o d} * \mathrm{YTCH}_{c, h, \text { mod }} \leq Y C_{h}
$$

$\forall c, h, \bmod , s c$

$$
\sum_{k} X R Q H M_{k, h, m, \text { mod }}^{\text {mod,sc }} \geq T M M I N_{\text {mod }} * Y T H M_{h, m, \text { mod }}
$$

$$
\sum_{k} X R Q H M_{k, h, m, m o d}^{\text {mod,sc }} \leq T M M A X_{\text {mod }} * Y T H M_{h, m, \bmod }
$$

$\forall c, m, \bmod , s c$

Capacity constraints

$$
\sum_{m} X Q S M_{s, m}^{s c} \leq C A P S_{S}
$$

$\forall s, s c$

$$
\sum_{p r} X P_{p r, m}^{s c} \leq C A P M_{m} * Y M_{m}
$$

$\forall m, s c$

$$
\sum_{m} \sum_{m o d} \sum_{p r} X Q M W_{p r, m, w}^{m o d, s c} \leq C A P W_{w} * Y W_{w}
$$

$\forall w, s c$

$$
\sum_{k} \sum_{c} \sum_{\bmod } X R Q C H_{\mathrm{k}, c, h}^{m o d, s c} \leq C A P H_{h} * Y C_{h}
$$


Auxiliary constraint for linearization.

$$
T C_{s c}-\sum_{s c} \rho_{s c} * T C_{s c}+\theta_{s c} \geq 0
$$

$\forall s C$

\subsubsection{Carbon cap policy}

In this policy, the following constraint is added to the proposed constraints (25-57) where the objective function remains the same.

$$
\begin{aligned}
& \sum_{m} \sum_{p r} E P_{m} * X P_{p r, m}^{s c} \\
& +\sum_{m} \sum_{w} \sum_{m o d} \sum_{p r} E T M W_{m, w, m o d} \\
& \text { * XQMW } W_{p r}^{\text {mod }, s c} \\
& +\sum_{w} \sum_{c} \sum_{\text {mod }} \sum_{p r} \sum_{p x} E T W C_{w, c, \text { mod }} \\
& \text { * XQW } W C_{p r}^{\text {mod,sc } s c}, \mathrm{w}, \mathrm{s} \\
& +\sum_{k} \sum_{c} \sum_{h} \sum_{m o d}^{r, p x, w, c} E T C H_{c, h, \text { mod }} \\
& \text { * XRQCH } H_{k, c, h}^{\text {mod,sc }} \\
& +\sum_{k} \sum_{h} \sum_{m} \sum_{m o d} E_{\text {mod }} M_{h, m, \bmod } \\
& \text { *XRQHM } M_{k, h, m}^{\text {mod,sc }} \\
& +\sum_{k} \sum_{h} E T D I P * D I S P_{\mathrm{k}, h}^{s c} \\
& \leq \text { Cap } \quad \forall s c
\end{aligned}
$$

\subsubsection{Carbon tax policy}

We add the following to equation (15) while the constraints remain the same.

$$
\begin{aligned}
& \operatorname{Tax} * \sum_{m} \sum_{p r} E P_{m} * X P_{p r, m}^{s c} \\
& +\sum_{m} \sum_{w} \sum_{\text {mod }} \sum_{p r} E T M W_{m, w, \bmod } \\
& \text { * XQMW } \mathrm{W}_{p r, m, w}^{\text {mod,sc }} \\
& +\sum_{w} \sum_{c} \sum_{m o d} \sum_{p r} \sum_{p x} E T W C_{w, c, \bmod } \\
& \text { *XQWC } C_{p r, p x, w, c}^{\text {mod,sc }} \\
& +\sum_{k} \sum_{c} \sum_{h} \sum_{m o d} E T C H_{c, h, \text { mod }} \\
& \text { * XRQCH } \mathrm{Hod}_{k, \mathrm{~s}, \mathrm{sc}} \\
& +\sum_{k} \sum_{h} \sum_{m}^{k, c, h} \sum_{m o d} E \mathrm{TH} H M_{h, m, \bmod } \\
& \text { *XRQHM } M_{k, h, m}^{m o d, s c} \\
& +\sum_{k} \sum_{h} E T D I P * D I S P_{k, h}^{s c}
\end{aligned}
$$

\subsubsection{Carbon cap-and-trade policy}

Equation (15) is modified so that the following is added to it

$$
C P^{+} * E C_{s c}^{+}-C P^{-} * E C_{s C}^{-}
$$

The following constraint is added to the proposed constraints (25) -(57)

$$
\begin{aligned}
& \sum_{m} \sum_{p r} E P_{m} * X P_{\mathrm{p} r, m}^{s c} \\
& +\sum_{m} \sum_{w} \sum_{m o d} \sum_{p r} E T M W_{m, w, \bmod } \\
& \text { * XQMW } W_{p r, m, w}^{\text {mod,sc }} \\
& +\sum_{w} \sum_{c} \sum_{\text {mod }} \sum_{p r} \sum_{p x} E T W C_{w, c, \bmod } \\
& \text { *XQWC } C_{p r, p x, w, c}^{\text {mod,sc }} \\
& +\sum_{k} \sum_{c} \sum_{h} \sum_{m o d} E_{\text {mod }} \mathrm{CH}_{c, h, \bmod } \\
& * X \mathrm{R} Q C H_{k, c, h}^{\text {mod }, s c} \\
& +\sum_{k} \sum_{h} \sum_{m} \sum_{\text {mod }} \text { ETHM }_{h, m, \bmod } \\
& \text { *XRQHM } M_{k, h, m}^{m o d, s c} \\
& +\sum_{k} \sum_{h} E T D I P * D I S P_{k, h}^{s c}+E C_{s c}^{-} \\
& \leq C a p+E C_{s c}^{+} \quad \forall s c
\end{aligned}
$$

\subsubsection{Carbon offset policy}

Equation (15) is modified so that the following is added to it

$$
O P * E C_{S C}^{+}
$$

The following constraint is added proposed constraints (25) (57)

$$
\begin{aligned}
& \sum_{m} \sum_{p r} E P_{m} * X P_{p r, m}^{s c} \\
& +\sum_{m} \sum_{w} \sum_{m o d} \sum_{p r} E T M W_{m, w, m o d} \\
& \text { * XQMW } W_{p r, m, w}^{\text {mod,sc }} \\
& +\sum_{w} \sum_{c} \sum_{m o d}^{p r, m, w} \sum_{p r} \sum_{p x} E T W C_{w, c, m o d} \\
& \text { * XQWC } C_{p r, p x, w, c}^{\text {mod,sc }} \\
& +\sum_{k} \sum_{c} \sum_{h} \sum_{m o d}^{r, p x, w, c} E T C H_{c, h, \text { mod }} \\
& * X R Q C \mathrm{H}_{k, c, h}^{\text {mod,sc }} \\
& +\sum_{k} \sum_{h} \sum_{m}^{k, c, h} \sum_{\text {mod }} E_{T H} M_{h, m, \bmod } \\
& \text { * XRQHM } M_{k, h, m}^{\text {mod,sc }} \\
& +\sum_{k} \sum_{h} E T D I P * D I S P_{k, h}^{s c} \\
& \leq C a p+E C_{s c}^{+} \quad \forall s c
\end{aligned}
$$

\section{Numerical example and results}

\subsection{Numerical example}

We consider a hypothetical CLSC network that consists of 3 plant centers, 3 warehouse locations, 3 collection centers and 6 market locations that include markets which demand only new products, only remanufactured products or both. Table 1, 2, 3 and 4 summarized some of the data considered in the model. Three road transportation modes are available to ship products between facilities in the CLSC where each mode has a specified size, carbon emission and a transportation cost. A flat substitution cost $=\$ 10$ is penalized for each product substituted. The numbers of EOL products returned and the 
demand of new and remanufactured products are considered uncertain. They are represented according to low returns/demand scenario, medium returns/demand scenario and high returns/demand scenario with a probability of $.2, .5$ and .3 respectively. In this example, we set $\lambda=1$ and $\omega=1000$. It is assumed that two components are required to produce one unit of product $\mathrm{CO}=2$. Moreover, $50 \%$ of returned products have minor defects, $30 \%$ have medium defects, $10 \%$ have high defects and $10 \%$ have serious defects. The carbon cap (CAP) is assumed to be $10,000 \mathrm{~kg}$ and the tax is $\$ 30 / \mathrm{kg}$. The cost of purchasing $\left(\mathrm{CP}^{+}\right)$, selling carbon $\left(\mathrm{CP}^{-}\right)$and offset price (OP) is $\$ 15 / \mathrm{kg}$. We used Lingo 18.0 to solve all four formulated mathematical models.

Table 1: General data.

\begin{tabular}{c|c}
\hline Parameters & Values \\
\hline$F M_{m}$ & Uniform $(500000,1500000)$ \\
$F W_{w}$ & Uniform $(400000,500000)$ \\
$F H_{h}$ & Uniform $(400000,450000)$ \\
$C A P M_{m}$ & Uniform $(1500,2500)$ \\
$C A P W_{w}$ & Uniform $(3000,3500)$ \\
$C A P H_{h}$ & Uniform $(1000,1500)$ \\
$C A P S_{s}$ & Uniform $(6000,7000)$ \\
$H C_{c}$ & Uniform $(5,10)$ \\
$E P_{m}$ & Uniform $(2.1,2.3)$ \\
\hline
\end{tabular}

Table 2: Uncertainty parameters data.

$\begin{array}{cccc}\text { Scenario } & \begin{array}{c}\text { New product } \\ \text { demand }\end{array} & \begin{array}{c}\text { Remanufactured } \\ \text { product demand }\end{array} & \begin{array}{c}\text { Number of } \\ \text { returned } \\ \text { products }\end{array} \\ \text { LOW } & \text { Uniform } & \text { Uniform }(245, & \begin{array}{c}\text { Uniform } \\ (200,230)\end{array} \\ \text { MED } & (350,450) & 315) & \text { Uniform } \\ & \text { Uniform } & \text { Uniform }(315, & (230,300) \\ \text { HIGH } & (450,550) & 385) & \text { Uniform } \\ & \text { Uniform } & \text { Uniform }(385, & (300,350)\end{array}$

Table 3: Transportation parameters data.

\begin{tabular}{c|cc}
\hline $\begin{array}{c}\text { Transportation } \\
\text { mode }\end{array}$ & Minimum capacity & Maximum capacity \\
\hline Heavy duty truck & 100 & 14,000 \\
Mid-size truck & 100 & 10,000 \\
Light truck & 100 & 5,000 \\
\hline
\end{tabular}

Table 4: Transportation mode capacities.

\begin{tabular}{c|cc}
\hline $\begin{array}{c}\text { Transportation } \\
\text { mode }\end{array}$ & $\begin{array}{c}\text { Trans. Cost } \\
(\$ / \text { ton-km) }\end{array}$ & $\begin{array}{c}\text { Carbon emission } \\
(\mathrm{kg} / \text { ton-km) }\end{array}$ \\
\hline Heavy duty truck & 0.125 & 0.297 \\
Mid-size truck & 0.118 & 0.0252 \\
Light truck & 0.11 & 0.048 \\
\hline
\end{tabular}

\subsection{Results}

Table (5) shows the results of running the proposed model using the above data. For each carbon regularity policy model, we demonstrate the solution of each scenario and its robust solution. It shows that the design variables, supplier selection, opening facilities and transportation mode selection are the same for all carbon regularity policy model. However, the quantity of components supplied from suppliers as well as products produced and shipped between facilities are different for every carbon regularity policy model.

\subsubsection{Results of carbon cap policy}

The results from this policy show that increasing the carbon cap increases the total cost of each scenario and lowers the value of the robust solution (Table 6 ). This is because more production activities are allowed, which increases the production cost, and at the same time, lowers the robust solution value since it is associated with infeasibility and shortage. Similarly, it is noticed that the higher the carbon emission allowed the higher the number of products substituted (Table 7).

Table 5: Results of CLSC network design under the four carbon policies.

\begin{tabular}{c|cccc}
\hline \multicolumn{1}{c}{} & Carbon cap & Carbon tax & $\begin{array}{c}\text { Carbon cap } \\
\text { and trade }\end{array}$ & $\begin{array}{c}\text { Carbon } \\
\text { offset }\end{array}$ \\
\hline SC1 & $1,672,571$ & $1,971,590$ & $1,765,601$ & $1,759,794$ \\
SC2 & $1,672,423$ & $2,084,539$ & $1,765,602$ & $1,765,602$ \\
SC3 & $1,670,867$ & $2,070,885$ & $1,765,601$ & $1,750,113$ \\
R0 & $2,336,050$ & $2,365,259$ & $2,038,502$ & $2,038,502$ \\
YM & M =2 & M =2 & M =2 & M =2 \\
YW & W =1 & W =1 & W =1 & W =1 \\
YC & H =2 & H =2 & H =2 & H =2 \\
Raw material & S1,S3 & S1,S3 & S1,S3 & S1,S3 \\
supplier & & & & \\
$\begin{array}{c}\text { Transportation } \\
\text { mode }\end{array}$ & MOD 2 & MOD 2 & MOD 2 & MOD 2 \\
\hline
\end{tabular}

Table 6: Carbon cap vs total cost of each scenario and robust solution.

\begin{tabular}{c|cccc}
\hline \multicolumn{5}{c}{ Total cost } \\
\hline Cap & SC1 & SC2 & SC3 & \\
6000 & $1,490,455$ & $1,445,632$ & $1,420,848$ & $3,577,456$ \\
8000 & $1,603,973$ & $1,560,199$ & $1,535,677$ & $2,927,227$ \\
10000 & $1,672,571$ & $1,672,423$ & $1,670,867$ & $2,336,050$ \\
12000 & $1,696,328$ & $1,746,395$ & $1,732,090$ & $2,019,296$ \\
14000 & $1,695,977$ & $1,745,963$ & $1,728,474$ & $2,018,863$ \\
\hline
\end{tabular}

Table 7: Carbon cap vs quantity of product substituted and carbon emitted each scenario.

\begin{tabular}{c|cccccc}
\hline \multicolumn{3}{|c}{ QWC (subs) } & \multicolumn{4}{c}{ Amount of carbon emitted } \\
\hline Cap & SC1 & SC2 & SC3 & SC1 & SC2 & SC3 \\
6000 & - & - & - & 6,000 & 6,000 & 6,000 \\
8000 & 296 & - & - & 8,000 & 8,000 & 8,000 \\
10000 & 727 & 179 & 84 & 9,169 & 10,000 & 10,000 \\
12000 & 727 & 645 & 414 & 9,732 & 11,967 & 11,996 \\
14000 & 727 & 645 & 100 & 10,732 & 13,199 & 13,352 \\
\hline
\end{tabular}

\subsubsection{Results of carbon tax policy}

As shown in table 8 and 9, when the tax value is neglected, the total cost of each scenario and the robust solution value is small and the quantity of the products substituted and the carbon emitted is high. Rising the tax value raises the total cost of each scenario and the robust solution value. The number of products substituted and amount of carbon emitted remains constant.

\subsubsection{Results of carbon cap-and-trade policy}

In this policy, the carbon cap $(10,000 \mathrm{~kg})$ and the price of purchasing or selling carbon is the same. Increasing the carbon selling and purchasing price results in an increase in each scenario and in the robust solution value (Table 10). This is due 
to the additional costs added to the objective function. However, the number of products substituted fluctuates with this increase. It is also noticed that the amount of carbon emitted is less in scenario 1 than in scenario 2 and 3 . As product demand increases, in scenario 2 and 3, the carbon emitted increases (Table 11).

Table 8: Carbon tax vs total cost of each scenario and robust solution

\begin{tabular}{|c|c|c|c|c|}
\hline & \multicolumn{3}{|c|}{ Total cost } & Ro \\
\hline $\operatorname{tax}$ & SC1 & SC2 & SC3 & \\
\hline 0 & $1,695,909$ & $1,745,863$ & $1,731,590$ & $2,018,763$ \\
\hline 15 & $1,834,058$ & $1,915,591$ & $1,899,547$ & $2,191,537$ \\
\hline 30 & $1,971,590$ & $2,084,539$ & $2,070,885$ & $2,365,259$ \\
\hline 45 & $2,109,122$ & $2,253,488$ & $2,242,222$ & $2,538,981$ \\
\hline 60 & $2,246,654$ & $2,422,437$ & $2,413,560$ & $2,712,703$ \\
\hline
\end{tabular}

Table 9: Carbon tax vs quantity of products substituted and carbon emitted in each scenario.

\begin{tabular}{l|llllll}
\hline \multicolumn{3}{|c}{ QWC (subs) } & \multicolumn{4}{c}{ Amount of carbon emitted } \\
\hline tax & SC1 & SC2 & SC3 & SC1 & SC2 & SC3 \\
0 & 727 & 645 & 186 & 10,925 & 13,484 & 13,700 \\
15 & 727 & 645 & 5 & 9,169 & 11,263 & 11,423 \\
30 & 727 & 645 & 5 & 9,169 & 11,263 & 11,423 \\
45 & 727 & 645 & 5 & 9,169 & 11,263 & 11,423 \\
60 & 727 & 645 & 5 & 9,169 & 11,263 & 11,423 \\
\hline
\end{tabular}

Table 10: Carbon purchasing/selling price vs total cost of each scenario and robust solution.

\begin{tabular}{c|cccc}
\hline \multicolumn{5}{c}{ Total cost } \\
\hline price & SC1 & SC2 & SC3 \\
5 & $1,752,961$ & $1,752,962$ & $1,752,961$ & $2,025,862$ \\
10 & $1,759,281$ & $1,759,282$ & $1,759,282$ & $2,032,182$ \\
15 & $1,765,601$ & $1,765,602$ & $1,765,601$ & $2,038,502$ \\
20 & $1,771,871$ & $1,771,922$ & $1,771,889$ & $2,044,822$ \\
25 & $1,778,221$ & $1,778,242$ & $1,778,236$ & $2,051,142$ \\
\hline
\end{tabular}

Table 11: Carbon purchasing/selling price vs quantity of product substituted and carbon emitted each scenario.

\begin{tabular}{l|llllll}
\hline \multicolumn{3}{|c}{ QWC (subs) } & \multicolumn{4}{c}{ Amount of carbon emitted } \\
\hline price & SC1 & SC2 & SC3 & SC1 & SC2 & SC3 \\
5 & 727 & 645 & 5 & 9,169 & 11,263 & 11,441 \\
10 & 727 & 645 & 493 & 9,169 & 11,263 & 11,480 \\
15 & 727 & 645 & 186 & 9,169 & 11,263 & 11,440 \\
20 & 727 & 645 & 5 & 9,169 & 11,263 & 11,423 \\
25 & 727 & 645 & 694 & 9,169 & 11,263 & 11,496 \\
\hline
\end{tabular}

\subsubsection{Results of carbon offset policy}

As in the carbon cap-and-trade policy, the carbon cap value is $(10,000 \mathrm{~kg})$ and we change the offset price. The shown results follow the trend of using the carbon cap-and-trade policy (Table 12,13).
Table 12: Carbon offset vs total cost of each scenario and robust solution.

\begin{tabular}{c|cccc}
\hline \multicolumn{5}{|c}{ Total cost } \\
\hline price & SC1 & SC2 & SC3 & \\
5 & $1,746,467$ & $1,749,924$ & $1,740,705$ & $2,029,125$ \\
10 & $1,753,071$ & $1,759,282$ & $1,742,718$ & $2,032,182$ \\
15 & $1,759,794$ & $1,765,602$ & $1,750,113$ & $2,038,502$ \\
20 & $1,766,191$ & $1,771,922$ & $1,767,131$ & $2,044,822$ \\
25 & $1,772,832$ & $1,778,242$ & $1,763,816$ & $2,051,142$ \\
\hline
\end{tabular}

Table 13: Carbon offset vs quantity of product substituted and carbon emitted each scenario

\begin{tabular}{l|llllll}
\hline \multicolumn{3}{|c}{ QWC (subs) } & \multicolumn{4}{c}{ Amount of carbon emitted } \\
\hline price & SC1 & SC2 & SC3 & SC1 & SC2 & SC3 \\
5 & 727 & 645 & 606 & 9,257 & 11,391 & 11,602 \\
10 & 727 & 645 & 6 & 9,169 & 11,263 & 11,441 \\
15 & 727 & 645 & 63 & 9,169 & 11,263 & 11,422 \\
20 & 727 & 645 & 893 & 9,169 & 11,263 & 11,487 \\
25 & 727 & 645 & 5 & 9,169 & 11,263 & 11,424 \\
\hline
\end{tabular}

\section{Conclusion}

In this paper, we presented a new way of designing a CLSC network by allowing product substitution using downward product substitution policy. We also considered four carbon regularity policies: the carbon cap policy, the carbon tax policy, the carbon cap-and-trade policy and the carbon offset policy. In the proposed model, uncertainties of product demand and number of returned products are taken into account. The robust optimization method is used to model the proposed problem. The results of the proposed model show that varying the carbon cap, the tax value, the selling and purchasing price of carbon and the offset price would affect the solution value of each proposed scenario, as well as the robust solution value. The same effect can be observed in the number of products substituted and the carbon emitted. The proposed model in this paper would benefit supply chain planners (the decision makers) as well as the companies who aim to switch from the traditional supply chain network to a closed loop supply chain network. For future work, different techniques to solve uncertainties, e.g. fuzzy programing and uncertainty set theory, can be implemented to solve the problem stated in this paper. In addition, the proposed model is based on a single period and a single product. Basing a model on multiple periods and multiple products would be a very interesting problem to investigate. Another possibility is to implement the proposed model on a real case study. In case of solving this problem on a large scale, using meta-heuristic algorithms would be very useful.

\section{References}

[1] Ilgin MA, Gupta SM. Reverse Logistics. Editor: Gupta SM Reverse Supply Chains: Issues and Analysis, 1-60, Boca Raton, FL, USA, CRC Press, 2013.

[2] Mohammed F, Selim SZ, Hassan A, Syed MN, "Multi-period planning of closed-loop supply chain with carbon policies under uncertainty". Transportation Research Part D Transport and Environment, 51, 146-172, 2017. 
[3] Diabat A, Abdallah T, Al-refaie A,. Svetinovic D, Govindan K. "Strategic Closed-Loop Facility Location Problem". IEEE Transactions on Engineering Management, 60(2), 398-408, 2013.

[4] Jin M, Granda-Marulanda NA, Down I. "The impact of carbon policies on supply chain design and logistics of a major retailer". Journal of Cleaner Prodoction, 85, 453-461, 2014.

[5] Benjaafar S, Li Y, Daskin M. "Carbon footprint and the management of supply chains: Insights from simple models". IEEE Transactions on Automation Science and Engineering, 10(1), 99-116, 2013.

[6] Mohajeri A, Fallah M. "A carbon footprint-based closedloop supply chain model under uncertainty with risk analysis: A case study". Transportation Research Part D Transport and Environment, 48, 425-450, 2016.

[7] He L, Hu C, Zhao D, Lu H, Fu X, Li Y. "Carbon emission mitigation through regulatory policies and operations adaptation in supply chains: theoretic developments and extensions". Natural Hazards, 84(1), 179-207, 2016.

[8] Fareeduddin M, Hassan A, Syed MN, Selim SZ. "The impact of carbon policies on closed-loop supply chain network design". Procedia CIRP, 26, 335-340, 2015.

[9] Gungor A, Gupta SM. "Issues in environmentally conscious manufacturing and product recovery: A survey". Computers \& Industrial Engineering, 36(4), 811-853, 1999.

[10] Ilgin MA, Gupta SM. "Environmentally conscious manufacturing and product recovery ( ECMPRO ): A review of the state of the art". Journal of Environmental Management, 91(3), 563-591, 2010.

[11] Wei J, Zhao J. "Reverse channel decisions for a fuzzy closed-loop supply chain". Applied Mathematical Modelling, 37(3), 1502-1513, 2013.

[12] Hong IH, Yeh JS. "Modeling closed-loop supply chains in the electronics industry: A retailer collection application". Transportation Research Part E: Logistics and Transportation Review, 48(4), 817-829, 2012.

[13] Pishvaee MS, Jolai F, Razmi J. "A stochastic optimization model for integrated forward/reverse logistics network design". Journal of Manufacturing Systems, 28(4), 107-114, 2009.

[14] Pochampally KK, Nukala S, Gupta SM. Strategic planning models for reverse and closed-loop supply chains. Boca Raton, Florida: CRC Press, 2009.

[15] Ferguson M. "Strategic and Tactical Aspects of ClosedLoop Supply Chains". Foundations and Trends® in Technology, Information and Operations Management, 3(2), 101-200, 2009.

[16] Jayaraman V, Guide VDR, Srivastava R. "A closed-loop logistics model for remanufacturing". Journal of the Operational Research Society, 50(5), 497-508, 1999.

[17] Beamon BM, Fernandes C. "Supply-chain network configuration for product recovery". Production Planning \& Control, 15(3), 270-281, 2004.

[18] Demirel NÖ, Gökçen H. "A mixed integer programming model for remanufacturing in reverse logistics environment". International Journal of Advanced Manufacturing Technology, 39(11-12), 1197-1206, 2008.

[19] Özceylan E, Paksoy T. "A mixed integer programming model for a closed-loop supply-chain network". International Journal of Production Research, 51(3), 718734, 2013.
[20] Kalaitzidou MA, Longinidis P, Georgiadis MC. "Optimal design of closed-loop supply chain networks with multifunctional nodes". Computers \& Chemical Engineering, 80, 73-91, 2015.

[21] Listeş 0. "A generic stochastic model for supply-andreturn network design". Computers \& Operations Research, 34(2), 417-442, 2007.

[22] Chouinard M, D'Amours S, Aït-Kadi D. "A stochastic programming approach for designing supply loops". International Journal of Production Economics, 113(2), 657-677, 2008.

[23] Soleimani H, Govindan K. "Reverse logistics network design and planning utilizing conditional value at risk". European Journal of Operational Research, 237(2), 487497, 2014.

[24] Qin Z, Ji X. "Logistics network design for product recovery in fuzzy environment". European Journal of Operational Research, 202(2), 479-490, 2010.

[25] Pishvaee MS, Torabi SA. "A possibilistic programming approach for closed-loop supply chain network design under uncertainty". Fuzzy Sets and Systems, 161(20), 2668-2683, 2010.

[26] Jindal A, Sangwan KS. "Closed loop supply chain network design and optimisation using fuzzy mixed integer linear programming model". International Journal of Production Research, 52(14), 4156-4173, 2014.

[27] Haddadsisakht A, Ryan SM. "Closed-loop supply chain network design with multiple transportation modes under stochastic demand and uncertain carbon tax". International Journal of Production Economics, 195, 118-131, 2018.

[28] Ilgin MA, Gupta SM, Battaïa O. "Use of MCDM techniques in environmentally conscious manufacturing and product recovery: State of the art". Journal of Manufacturing Systems, 37, 746-758, 2015.

[29] Gupta SM, Ilgin MA. Multiple Criteria Decision Making Applications in Environmentally Conscious Manufacturing and Product Recovery. Boca Raton, Florida: CRC Press, 2018.

[30] Amin SH, Zhang G. "Closed-loop supply chain network configuration by a multi-objective mathematical model". International Journal of Business Performance and Supply Chain Modelling, 6(1), 1-15, 2014.

[31] Shi J, Liu Z, Tang L, Xiong J. "Multi-objective optimization for a closed-loop network design problem using an improved genetic algorithm". Applied Mathematical Modelling, 45, 14-30, 2016.

[32] Nukala S, Gupta SM. "Strategic and tactical planning of a closed-loop supply chain network under uncertainty". SPIE International Conference on Environmentally Conscious Manufacturing VI, Boston, USA, 01-03 October 2006.

[33] Amin SH, Zhang G. "A multi-objective facility location model for closed-loop supply chain network under uncertain demand and return". Applied Mathematical Modelling, 37(6), 4165-4176, 2013.

[34] Paksoy T, Pehlivan NY, Özceylan E. “Fuzzy Multi-Objective Optimization of a Green Supply Chain Network with Risk Management that Includes Environmental Hazards". Human and Ecological Risk Assessment: An International Journal, 18(5), 1120-1151, 2012. 
[35] Pishvaee MS, Rabbani M, Torabi SA. "A robust optimization approach to closed-loop supply chain network design under uncertainty". Applied Mathematical Modelling, 35(2), 637-649, 2011.

[36] Özceylan E, Paksoy T. "Interactive fuzzy programming approaches to the strategic and tactical planning of a closed-loop supply chain under uncertainty". International Journal of Production Research, 52(8), 23632387, 2014.

[37] Jindal A, Sangwan KS. "Multi-objective fuzzy mathematical modelling of closed-loop supply chain considering economical and environmental factors". Annals of Operations Research, 257(1-2), 95-120, 2017.

[38] Zhen L, Huang L, Wang W. "Green and sustainable closedloop supply chain network design under uncertainty". Journal of Cleaner Prodoction, 227, 1195-1209, 2019.

[39] Ahiska SS, Gocer F, King RE. "Heuristic inventory policies for a hybrid manufacturing/remanufacturing system with product substitution". Computers \&. Industrial Engineering, 114, 206-222, 2017.

[40] Ghafarimoghadam A, Karimi A, Mousazadeh M, Pishvaee MS. "A robust optimisation model for remanufacturing network design problem with one-way substitution". International Journal of Services and Operations Management, 24(4), 484-503, 2016.

[41] Fahimnia B, Sarkis J, Dehghanian F, Banihashemi N, Rahman S. "The impact of carbon pricing on a closed-loop supply chain: An Australian case study". Journal of Cleaner Prodoction, 59, 210-225, 2013.

[42] Mohammed F, Hassan A, Selim SZ. "Carbon market sensitive robust optimization model for closed loop supply chain network design under uncertainty". Journal of Physics: Conference Series, 1150(1), 1-10, 2019.

[43] Shin H, Park S, Lee E, Benton WC. "A classification of the literature on the planning of substitutable products". European Journal of Operational Research, 246(3), 686699, 2015.
[44] Lang JC. "Production and inventory management with substitutions". Lecture Notes in Economics and Mathematical Systems, 636, 1-258, 2010.

[45] Bayindir ZP, Erkip N, Güllü R. "Assessing the benefits of remanufacturing option under one-way substitution". Journal of the Operational Research Society, 56(3), 286296, 2005.

[46] Bayindir ZP, Erkip N, Güllü R. "Assessing the benefits of remanufacturing option under one-way substitution and capacity constraint". Computers \& Operations Research, 34(2), 487-514, 2007.

[47] Li Y, Chen J, Cai X. "Uncapacitated production planning with multiple product types, returned product remanufacturing, and demand substitution". OR Spectrum, 28(1), 101-125, 2006.

[48] Piñeyro P, Viera 0. "The economic lot-sizing problem with remanufacturing and one-way substitution," Int. J. Prod. Econ., 156, 167-168, 2010.

[49] A. Choudhary, S. Sarkar, S. Settur, and M. K. Tiwari, "A carbon market sensitive optimization model for integrated forward-reverse logistics". International Journal of Production Economics, 164, 433-444, 2015.

[50] Mulvey JM, Vanderbei RJ, Zenios SA. "Robust Optimization of Large-Scale Systems". Operations Research, 43(2), 264281, 1995.

[51] Yu C, Li H. "A robust optimization model for stochastic logistic problems". International Journal of Production Economics, 64(1-3), 385-397, 2000.

[52] Li HL, "An efficient method for solving linear goal programming problems". Journal of Optimization Theory and Applications, 90(2), 465-469, 1996. 